\title{
Os Regimes Políticos e as Guerras Civis: Uma Discussão Metodológica
}

\author{
Danilo Freire ${ }^{l}$
}

\begin{abstract}
Resumo
A guerra civil é uma das formas de violência coletiva mais importante de nossa época. Embora a literatura tenha destacado a relação entre determinadas variáveis e 0 início das guerras civis, a influência dos regimes políticos nos conflitos internos ainda é controversa. 0 presente estudo visa colaborar para esse debate. Os objetivos deste artigo são: discutir as definições contemporâneas de guerras civis; avaliar, criticamente, as bases quantitativas mais comuns nos estudos de política comparada e comentar sua adequação para as pesquisas sobre guerras civis e; por último, sugerir possíveis soluções metodológicas que poderiam ser utilizadas para analisar, com mais precisão, o impacto dos regimes no início das guerras civis.
\end{abstract}

Palavras-chave: Guerra civil. Regimes políticos. Bases de dados.

\section{Political Regimes and Civil Wars}

\begin{abstract}
Civil war is one of the most important forms of collective violence of our time. Although literature has stressed the relation between certain variables and the onset of civil wars, the influence of political regimes on internal conflicts remains controversial. The present study aims to collaborate with this debate. The objectives of this article are: discussing the current definitions of civil war; critically evaluating the quantitative database most widely used in the studies of Comparative Politics, and commenting
\end{abstract}

\footnotetext{
${ }^{1}$ Mestrando do Departamento de Ciência Política. Universidade de São Paulo, Brasil. danilofreire@ gmail.com
} 
about their adequacy to civil war research; and suggesting possible methodological solutions that could be used to analyze the impact of political regimes on civil wars more accurately.

Keywords: Civil war. Political regimes. Datasets

\section{INTRODUÇÃ̃O}

guerra civil ${ }^{2}$ é uma das formas de conflito coletivo mais importante de nossa
época. Uma breve análise do período posterior à Segunda Guerra Mundial
nos mostra que, se comparadas às disputas militares entre estados soberanos, as guerras civis contemporâneas são assustadoramente freqüentes e violentas. Entre 1945 e 2004, a humanidade passou por 25 guerras internacionais, com cerca de 3,3 milhões de vítimas; as guerras civis, em contrapartida, eclodiram 140 vezes neste mesmo período (SAMBANIS, 2004a, p. 259), atingindo aproximadamente $40 \%$ de todos os países com população superior a meio milhão de habitantes (FEARON, 2005, p. 1) e deixando ao menos 20 milhões de mortos e 67 milhões de refugiados (COLLIER; SAMBANIS, 2005, p. xiii). Estas estimativas, no entanto, não levam em consideração o número de vítimas indiretas das guerras civis, já que em um cenário de elevada violência interna é bastante comum o aparecimento de epidemias, crises de fome e sérias falhas nos serviços de saúde pública (GHOBARAH; HUTH; RUSSETT, 2004). Se fossem incluídas no cálculo todas as pessoas atingidas por tais calamidades, certamente chegaríamos a estatísticas ainda mais impressionantes.

Os fatores políticos, com efeito, são cruciais para compreendermos os processos que levam um país a uma guerra civil. Vários estudos recentes indicam, por exemplo, que mudanças abruptas no regime político (HEGRE et al., 2001), repressão governamental (ZIMERMAN; ALVES, 2007), ou forte centralismo administrativo (LAKE; ROTHCHILD, 1996) podem tornar um país mais suscetível a um conflito interno. Já o impacto dos regimes políticos na incidência das guerras civis, entretanto, não é unânime na academia, e um dos pontos mais controversos desta discussão são as muitas dúvidas a respeito dos métodos utilizados para

\footnotetext{
${ }^{2}$ Usaremos, neste trabalho, os termos "guerra civil", "guerra doméstica", "guerra interna", "conflito civil" e "conflito doméstico" como sinônimos.
} 
incorporar os regimes nas análises quantitativas (STRAND, 2007; VREELAND, 2008).

0 presente estudo visa colaborar para esse debate. Os objetivos deste artigo são: (i) discutir as definições contemporâneas de guerras civis; (ii) avaliar, criticamente, as bases quantitativas mais comuns nos estudos de política comparada e comentar sua adequação para as pesquisas sobre guerras civis e (ii) sugerir possíveis soluções metodológicas que poderiam ser utilizadas para analisar, com mais precisão, o impacto dos regimes no início das guerras civis. A tarefa é de grande importância para as análises empíricas e, apesar de já existir uma discussão a respeito destas questões no exterior, ainda não há, enquanto sabemos, qualquer publicação nacional sobre o tema. Dessa forma, é possível preencher um espaço ainda inexplorado pelos cientistas políticos brasileiros.

\section{Definindo as Guerras Civis}

Definir uma guerra civil é tarefa difícil. Ainda que, intuitivamente, possamos imaginar o que seja uma guerra civil, livrar o fenômeno de sua forte carga semântica e defini-lo em termos precisos, a fim de torná-lo útil para as pesquisas acadêmicas, demanda um grande esforço intelectual. Stathis Kalyvas, visando dar maior clareza a este conceito politicamente ambíguo, estabelece uma útil tipologia da violência interna. A partir de dois eixos, a produção e a intenção da violência, o autor classifica quatro "tipos ideais" de conflitos internos, mostrando em termos claros e precisos a diferença entre eles: o terror de estado; o genocídio; o extermínio recíproco e a guerra civil (KALYVAS, 2006, p. 29). A guerra civil, para o autor, pode ser definida como uma forma de violência que contém ao menos dois atores distintos, sendo que ambos possuem "monopólios da violência parciais ou sobrepostos" em determinado território nacional (KALYVAS, 2006, p. 31). No entanto, é importante destacar que, em uma guerra civil, os grupos devem possuir um propósito eminentemente político e não puramente criminoso. Como bem ilustra Zimerman (2008, p. 33), mesmo se o Primeiro Comando da Capital ou o Comando Vermelho fizessem um grande número de vítimas em seus ataques, ainda assim o Brasil não estaria em uma guerra civil, uma vez que estes grupos não visam desafiar a soberania nacional. Apenas se fossem incorporadas demandas visivelmente políticas às suas atitudes poder-se-ia considerar a existência de uma guerra civil em nosso País. 
Quadro 1 - Tipologia de Violência Coletiva

\begin{tabular}{|c|c|c|}
\hline & $\begin{array}{c}\text { Intenção da violência: o ator político deseja governar } \\
\text { a população-alvo }\end{array}$ \\
\hline Produção da Violência & Sim & Não \\
\hline Unilateral & Terror de estado & Genocídio e deportação em massa \\
\hline Bilateral/Multilateral & Violência de guerra civil & Extermínio recíproco \\
\hline
\end{tabular}

Fonte: Kalyvas (2006, p. 29).

A classificação sugerida por Kalyvas, todavia, também possui um problema. Sua definição mostra-se pouco operacionalizável, já que ela não menciona qualquer número de base, um threshold mínimo, a partir do qual um evento possa ser classificado, de modo relativamente consensual, como uma guerra civil.

Se quisermos, contudo, estabelecer alguma cifra de referência, por onde deveríamos começar? A medida mais utilizada para diferenciar entre paz e guerra civil é o número de mortes diretamente relacionadas aos combates. Um dos primeiros bancos de dados a contabilizar tais estatísticas foi o Correlates of War (COW), projeto iniciado em 1963 por J. David Singer na Universidade de Michigan, que estabelece o número de 1000 mortos durante todo o conflito para que seja constatada a existência de uma guerra civil (SARKEES; SCHAFER, 2000, p. 129). 0 COW foi amplamente utilizado pelos pesquisadores durante mais de três décadas e, ao que parece, serviu de padrão para as muitas bases quantitativas compiladas recentemente (SAMBANIS, 2004b, p. 814-815).

Certos autores, entretanto, levantam dúvidas a respeito da utilização da quantidade de mil mortos como um limite mínimo para se identificar uma guerra civil. 0 número, além de sabidamente arbitrário, gera um viés de seleção em favor dos conflitos ocorridos em países mais populosos, pois neles é mais fácil de obter o quociente de vítimas necessário para que um conflito seja caracterizado como guerra civil (ZIMERMAN, 2008, p. 31). Uma base de dados que visa minimizar este problema é o Armed Conflict Database (ACD) (GLEDITSCH et al., 2002), criado por meio de um esforço conjunto entre o Uppsala Conflict Database Project (UCDP) e o Peace Research Institute Oslo (PRIO). 0 ACD traz uma importante contribuição à análise dos confrontos internos, pois além de seguir o tradicional critério de definição de guerras civis, o número mínimo de mil 
vítimas diretas durante um ano, ele inclui também uma nova categoria, os conflitos civis menores (minor armed conflict), que são codificados a partir da marca de apenas 25 indivíduos mortos diretamente em combate (GLEDITSCH et al., 2002, p. 617). 0 total de 25 mortes ao ano, embora também arbitrário, foi escolhido por ser, de acordo com os autores, "[...] alto o suficiente para a violência representar um evento politicamente significativo, embora o preciso impacto local e internacional [de tal violência] possa variar" (GLEDITSCH et al., 2002, p. 617). Dessa forma, podem-se conceber ao menos duas possibilidades para mensurarmos os conflitos civis e analisarmos sua intensidade, o que talvez corresponda melhor às necessidades dos pesquisadores.

Gráfico 1 - Intensidade dos Conflitos Civis

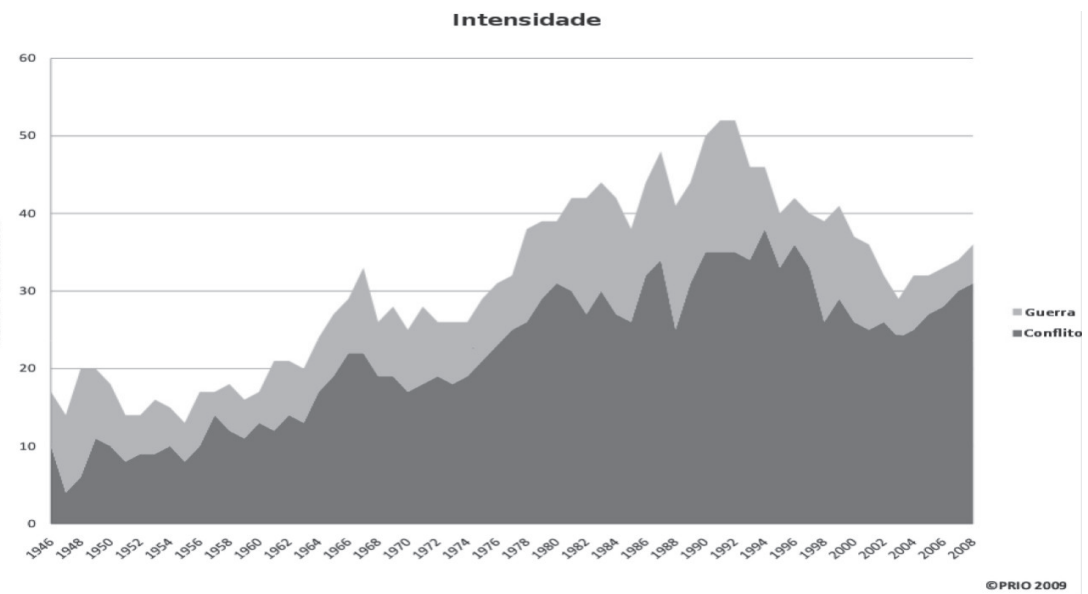

Fonte: UCDP/PRIO, 2009.

\section{Os Regimes Políticos e as Guerras Civis}

Embora ainda não exista um modelo geral para as guerras internas, a literatura quantitativa tem mostrado, em um grande número de estudos empíricos, que determinados elementos estão fortemente associados ao início dos conflitos civis. Dentre as variáveis mais robustas se destacam: grande população nacional, baixa renda per capita, baixo crescimento econômico e, em menor grau, heterogeneidade étnica e terreno montanhoso têm sido consistentemente 
méncionados como fatores que impulsionam a incidência de uma guerra civil (BLATTMAN; MIGUEL, 2010; COLLIER; HOEFFLER, 2004; DIXON, 2009; FEARON; LAITIN, 2003; HEGRE; SAMBANIS, 2006). Já a relação direta entre regimes políticos e guerras civis é ainda controversa. 0 problema não deixa de ser curioso, pois apesar de muitos conflitos terem como justificativa, ao menos no plano retórico, a luta pela democracia e pela liberdade, os dados estatísticos não têm mostrado uma correlação clara entre regime político e guerras civis. De fato, dos 27 artigos analisados por Dixon que incluíram a variável "democracia" em seus modelos, 19 não foram capazes de encontrar uma relação significativa entre ela e a ocorrência de guerras civis, dois artigos encontraram uma relação negativa entre as duas, e cinco trabalhos apontam que existe uma relação positiva entre elas, na qual a democracia aumenta as chances de um país entrar em guerra civil (DIXON, 2009, p. 718). A maior parte dos autores que encontrou uma ligação entre regimes políticos e guerras civis, contudo, aponta que ela tem a forma de um "U invertido", na qual dois extremos do espectro político possuem baixa incidência de guerras civis e há uma concentração de rebeliões em "anocracias" ou "regimes híbridos", aqueles se encontram em escalas intermediárias, possuindo tanto características de democracias quanto de autocracias (FEARON; LAITIN, 2003; HEGRE et al., 2001). Entretanto, há autores que dizem que tal ligação é espúria, uma vez que ela deriva de problemas de codificação dos índices de democracia mais utilizados nas análises de conflitos domésticos (STRAND, 2007; VREELAND, 2008). Dessa forma, uma revisão de tais índices se faz necessária caso quisermos avançar nesse sentido. Começaremos então pela análise do banco de dados políticos mais utilizado nos estudos de guerras civis (VREELAND, 2008, p. 403), o Polity IV (MARSHALL; GURR; JAGGERS, 2009).

\section{Polity IV}

0 Political Regime Characteristics and Transitions, criado por Ted Gurr em 1974 e atualmente em sua quarta versão (Polity IV), é o índice de democracia mais utilizado nos estudos de política comparada. No entanto, o índice possui alguns problemas quando utilizado nas análises de guerras civis. Strand (2007) mostra como boa parte da ligação entre regimes híbridos e guerras civis encontrada na literatura é derivada do elemento "faccionalismo" presente neste índice. Com efeito, a categoria 2 de PARREG (Regulação da Participação: Faccional ou Transitória), é definida no Polity II como uma situação na qual 
[...] grupos políticos relativamente estáveis e duradouros que competem por influência política em nível nacional - partidos, grupos regionais ou 'facções', não necessariamente eleitos - mas a competição entre eles é intensa hostil e freqüentemente violenta. Faccionalismo extremo pode se manifestar no estabelecimento de governos rivais e em guerras civis. (GURR, 1989 apud STRAND, 2007, p. 3, grifo nosso).

Assim, existe uma relação tautológica entre essa variável e as guerras civis. De fato, nos dados utilizados por Hegre et al (2001), 72\% dos regimes intermediários (situados no centro da escala do Polity) são codificados como faccionais, e duas de cada três guerras civis (88 de 132 conflitos) acontecem em governos de facções (STRAND, 2007, p. 3). Ao replicar este trabalho tanto com dados do Polity III quanto os do Polity IV e usando variável dummy para medir o "faccionalismo" nos dois índices³, Strand (2007, p. 14-15) não encontra evidência alguma da relação entre regimes híbridos e guerras civis, mas sua variável "faccionalismo" aparece como significativa em todos os modelos.

Vreeland (2008) também mostra algumas dificuldades para se utilizar o Polity nos trabalhos de guerras civis. Além de mencionar os problemas descritos por Strand (2007), o autor aponta ainda outro problema que pode contribuir para sobrerepresentar os regimes híbridos nos estudos que relacionam formas de governo e guerras civis:

Para algumas observações, os valores específicos para os cinco componentes [do Polity] estão faltando, e [os autores] colocam valores interpolados para essas observações. Por exemplo, observações [descritas como] 'interregno' ou 'anarquia' são codificadas como 0 (em uma escala de - 10 a + 10, codificandoas portanto como anocracias), e observações [marcadas como] 'transição de regime' são codificadas como a média do primeiro e do último Polity Scores antes e depois da transição. Os mantenedores dos dados avisam que tais observações "são especialmente propícias ao início de violência política; como tais, esses casos especiais, embora relativamente raros (eles constituem apenas cerca de 4\% dos casos anuais) são um grupo extremamente enviesado (VREELAND, 2008, p. 406-407).

Vreeland realiza então duas análises estatísticas, replicando os modelos de Hegre et. al. (2001) e Fearon e Laitin (2003), e em nenhum dos casos foi encontrada

\footnotetext{
${ }^{3}$ Strand (2007, p. 4) codificou essa variável binária como '1' quando PARREG tem os valores de '2' ou ' 3 ' ou se PARCOMP tem o valor de ' 3 ', e '0' em todos os outros casos.
}

OS REGIMES POLÍTICOS E AS GUERRAS CIVIS... 
uma relação significativa entre o "U invertido" e as guerras civis (VREELAND, 2008). Apenas em um dos componentes, a competitividade da participação (PARCOMP), foi possível visualizar tal relação; contudo, nessa variável, o valor intermediário (3, de uma escala de 1 a 5) se refere justamente a "competição faccional", o qual possui claras referências às guerras internas em sua codificação (VREELAND, 2008). Como conclusão, Vreeland escreve que

[...] a escala agregada do Polity não deve ser empregada para testar hipóteses sobre regimes e guerras civis no futuro. [...] Meu trabalho sugere que devemos empregar variáveis mais claramente definidas para capturar os efeitos das instituições políticas. [...] Nós certamente não devemos agrupar poderes executivos, eleições e violência política em uma única escala para entender a relação entre guerra civil e instituições políticas (VREELAND, 2008, p. 419420).

Dessa forma, temos que apesar de ser o índice de democracia prevalente nas análises de guerras civis, o Polity possui graves problemas de codificação, os quais, em larga medida, tornam problemático o uso de seus dados em forma agregada. Com efeito, o Polity têm sido de grande utilidade para os estudos de Política Comparada e Relações Internacionais, embora para analisar nosso objeto de pesquisa, as guerras civis, ele não é totalmente adequado.

\section{FREEDOM IN THE WORLD}

0 Freedom in the World é outro índice bastante utilizado nos estudos empíricos. Produzido pela Freedom House, uma organização norte-americana fundada em 1941 com o propósito de promover os ideais democráticos pelo mundo, o Freedom in the World é um relatório anual que avalia a presença de direitos políticos e liberdades civis em todos os países do globo. No que tange às guerras civis, o uso do Freedom in the World é ainda mais problemático do que o do Polity $I V$. Embora o Polity codifique categorias que fazem referência às guerras civis, ainda há duas possíveis saídas para tornar seus dados relativamente úteis para 0 pesquisador de conflitos internos: por um lado, pode-se retirar do índice agregado as variáveis que possuem endogeneidade com os conflitos e montar uma nova classificação, já que o Polity oferece os dados de seus componentes em separado e seu esquema de codificação é claro; e, por outro lado, se a intenção do pesquisador é medir o impacto de algum fator político específico nas guerras domésticas, ele 
também pode utilizá-las isoladamente ou em alguma outra combinação que lhe seja interessante. Com o Freedom in the World, em contrapartida, não há como realizar nenhuma dessas operações: como os dados desagregados dos itens que formam as categorias maiores do Freedom in the World não estão disponíveis para consulta (STOHL et al., 1986, p. 598-599), não há qualquer possibilidade de se reavaliar ou modificar, a fim de melhor acompanhar distintos interesses, alguma das 10 questões referentes aos direitos políticos ou das 15 referentes às liberdades civis incluídas naquele índice (VREELAND, 2008, p. 414). Este banco de dados, assim como o Polity $I V$, também faz clara menção à violência política em sua codificação, como vemos na pergunta $\mathrm{F} 3$ utilizada para formular o índice ("[A população] está livre de guerras e insurgências?") e na descrição das "características gerais" das classificações dos direitos políticos ("Qualificação 7 [menos livre] - Países e territórios com uma qualificação 7 têm poucos ou nenhum direito político por causa de severa opressão governamental, às vezes junto com uma guerra civil" (FREEDOM HOUSE, 2010). Como não é possível retirar dos dados as variáveis contaminadas, é fácil concluir que o Freedom in the World não é recomendado para os estudos de guerras civis, já que os vários problemas de sua codificação certamente trarão vieses nos trabalhos de guerras internas.

\section{Polyarchy Dataset}

0 Polyarchy Dataset foi originalmente produzido por Tatu Vanhanen a partir de suas pesquisas sobre democracia nos anos 1960 (VANHANEN, 2000, p. 252), e teve sua primeira versão lançada em 1984, analisando as duas dimensões

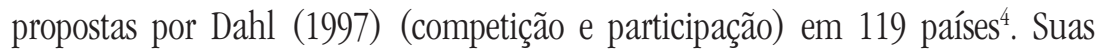
edições posteriores foram feitas em parceria com o Institute for Peace Research de Oslo (PRIO), e os dados mais recentes abarcam 187 estados durante o período de 1810 a 2002.

Pelo fato do índice de Vanhanen possuir apenas duas variáveis baseadas apenas em propriedades observáveis das eleições (STRAND, 2006, p. 22), os procedimentos de mensuração e agregação são marcadamente mais simples do que nos outros bancos que discutimos acima. A competição é definida como o

\footnotetext{
${ }^{4} 0$ índice possui o nome de Polyarchy Dataset justamente por medir as categorias de Dahl (1997), mas ele também é conhecido pelo nome de seu autor, Vanhanen.
}

OS REGIMES POLÍTICOS E AS GUERRAS CIVIS...

D. FREIRE • 243 
total de votos do maior partido subtraídos de 100, e a participação pelo total da população que tomou parte no pleito (VANHANEN, 2000, p. 253).

Para os estudos de guerras civis, as variáveis propostas por Vanhanen são perfeitamente utilizáveis, uma vez que elas não fazem qualquer referência a formas de violência civil em suas codificações (VREELAND, 2008, p. 415). Mas elas possuem outros problemas que podem afetar a qualidade das análises empíricas. Em primeiro lugar, há um grande viés do índice em favor dos países com sistema político fragmentado: um sistema político no qual o partido dominante vence por uma margem estreita de votos é considerado mais democrático do que outro onde o maior partido ganha as eleições com ampla maioria (GATES et al., 2006, p. 897). Um país no qual o maior partido tenha $25 \%$ dos votos é considerado duas vezes mais democrático do que outro cujo partido vencedor ganhou $63 \%$ da votação (HEGRE, 2003, p. 17); com isso, é possível imaginar, por exemplo, que 0 Brasil ou a Itália, países com estruturas políticas conhecidamente fragmentadas, sejam considerados talvez mais democráticos do que países que adotam o modelo bipartidário, como a Inglaterra. Em segundo lugar, há problemas no que se refere aos votos. Países que possuem leis que tornam compulsório o exercício do voto tendem a ter a participação artificialmente inflada no índice de Vanhanen, também fazendo com que eles pareçam mais democráticos quando o resultado final é computado. Ademais, como admite o próprio autor, países desenvolvidos, que tendem a possuir uma população adulta maior do que países em desenvolvimento, também serão sobrerepresentados no que toca à participação (VANHANEN, 2000, p. 255) e, por conseguinte, serão vistos como mais democráticos. Tais deficiências podem gerar sérias distorções na classificação de democracias, talvez até maiores do que as produzidas pelo Polity IV ou o Freedom in the World. Embora não tenha problemas de endogeneidade com as guerras civis e suas variáveis sejam definidas de modo claro, o Polyarchy Dataset deve ser usado com cautela nos estudos da área, em grande medida graças a seus próprios problemas de operacionalização.

\section{Database of Political Institutions}

0 último banco de dados que avaliaremos neste trabalho é o Database of Political Institutions (DPI), criado em 2001 por Philip Keefer e demais membros do Grupo de Pesquisas sobre Desenvolvimento do Banco Mundial (BECK et al., 2001). De todas as bases que apresentamos aqui, o DPI é a única que não oferece qualquer sugestão metodológica para calcularmos um índice de democracia: os 
autores preferiram disponibilizar as variáveis de maneira desagregada, deixando a tarefa de combiná-las a cargo de cada pesquisador. Essa decisão, a nosso ver acertada, faz do DPI um dos bancos de dados mais flexíveis da área de Política Comparada. Ao contrário do Freedom in the World e do Polity IV, por exemplo, o DPI traz em seu manual informações bastante detalhadas a respeito da codificação de suas variáveis, das fontes adotadas. Mas, como veremos à frente, ele também possui suas limitações, algumas delas consideráveis, que podem afetar os estudos de guerras civis.

Para melhor compararmos o DPI com os demais índices resenhados neste capítulo, levaremos em consideração apenas as variáveis dessa base que correspondem às duas dimensões descritas por Dahl (1997), competição e participação, já que ambas aparecem em todos os outros bancos que discutimos até aqui. A competição, no DPI, é medida basicamente por dois elementos, o Índice de Competitividade Eleitoral do Legislativo (LIEC) e o Índice de Competitividade Eleitoral do Executivo (EIEC) (BECK et al., 2001, p. 166; KEEFER, 2010, p. 1516). Ambos são classificados em uma escala de 1 a 7.

Esse índice, entretanto, possui um grave inconveniente para as pesquisas sobre guerras civis: há em suas variáveis uma menção à violência civil, e ela dificilmente pode ser removida sem trazer prejuízo à análise. Na classificação do DPI,

Assembléias funcionando sob condições de guerra civil ou onde há luta política em um país cujo resultado é que as instituições não controlam a maior ou a mais importante parte do território, são marcadas como 1. [Tal procedimento] ocorre independentemente de quão competitivas foram as eleições para a assembléia e quais seus poderes formais (KEEFER, 2010, p. 15).

Pode-se supor que uma solução para este problema seria a simples exclusão da categoria problemática da escala final, uma vez que as demais variáveis não estão contaminadas. A prática, entretanto, induzir-nos-ia a um erro, já que é possível que os valores de '1 - Sem legislatura' não apenas se refiram a países que enfrentam guerras civis, mas também a exemplos de ditadura nos quais não existe qualquer tipo de poder legislativo. Com efeito, a competitividade do legislativo no Bahrein, por exemplo, é marcada no DPI como '1' de 1976 a 2002, e o país não teve nenhuma guerra civil no período; já o Irã e o Zimbábue, 
em contrapartida, possuem um único ano cuja competitividade assume o valor de '1', 1980, provavelmente refletindo as turbulências ocorridas em ambos os países no ano anterior (a Revolução Islâmica e a guerra civil de independência), sem ligação com o fato desses países não possuírem legislativos eleitos. Assim, pelo fato de dois fenômenos distintos estarem incluídos na mesma codificação, sendo um deles a presença de guerra civil, o uso dessa variável nos modelos estatísticos que analisam o início de conflitos internos não é recomendado. Enquanto sabemos, esse problema não foi identificado pelos pesquisadores, uma vez que não nos foi possível encontrar nenhum artigo mencionando esta questão.

0 índice de competitividade eleitoral do executivo (EIEC) é codificado na mesma escala apresentada acima (KEEFER, 2010, p. 16), e nele também encontramos alguns pontos passíveis de crítica. Por um lado, embora para 0 EIEC não haja problemas em se aplicar a codificação 1 encontrada no LIEC (Sem legislativo), pois em todas as situações nas quais existem grupos rivais lutando pelo executivo é razoável supor que este poder tenha sua influência bastante restrita, o que de certa forma justifica sua classificação como "Sem executivo"; por outro lado, uma das codificações dispostas no LIEC não possui sentido quando aplicada às eleições do poder executivo: '5 - Vários partidos são legais, mas apenas um recebeu cadeiras'. Em uma eleição majoritária, como é o caso da escolha presidencial, todos os pleitos darão a cadeira a um dos partidos, por mais aberto e competitivo que tenha sido o processo. Assim, não é correto afirmar que esta classificação seja menos democrática do que as duas últimas quando aplicadas à escolha do executivo, o que constitui um grave erro de codificação no DPI. Com efeito, em uma comunicação privada, Philip Keefer concordou que "[...] de fato, a versão 2010 do DPI possui 5900 observações, mas somente 15 casos de EIEC = 5; eu acho que eles provavelmente são erros [de codificação]". A escala, dessa forma, talvez devesse ser recalculada a fim de evitar estes inconvenientes; porém, como o número de casos envolvendo tanto os valores de ' 1 ' e de ' 5 ' no EIEC é muito pequeno (35 e 15, respectivamente), provavelmente não haveria grandes problemas para as análises estatísticas se eles fossem marcados como missings. Como os dados estão disponíveis em escala desagregada, realizar essa operação é uma tarefa fácil.

Quanto à participação, o DPI não oferece qualquer medida que a avalie diretamente. 0 índice não traz qualquer informação a respeito do voter turnout ou da existência de restrições legais impostas ao exercício do voto, deixando a 
dimensão participativa de fora da análise dos autores. Essa omissão, certamente importante, faz com que o DPI não possa ser perfeitamente comparado com os índices de democracia que mencionamos acima, um problema caso quisermos estender a validade de uma determinada relação estatística utilizando mais de uma medida sobre os regimes políticos.

\section{Conclusã̃o}

Como vimos neste trabalho, a relação entre as guerras internas e os índices de democracia é problemática. Nenhuma das bases de dados sobre regimes políticos são perfeitamente adequadas para a análise desse objeto de estudo, seja por incluírem em suas codificações elementos conflitantes com os pressupostos dos estudos de guerras civis, seja pela pouca atenção dada à operacionalização das variáveis a partir de um marco teórico mais consistente (MUNCK; VERKUILEN, 2002 , p. 5). Mas quais seriam, por fim, os melhores caminhos para os pesquisadores interessados em analisar a influência das formas de governos sobre os conflitos internos?

Nossa primeira sugestão é procurar os índices que possuem menor potencial para endogeneidade com as guerras civis. Nesse sentido, destaca-se 0 índice de Vanhanen (2000). Embora o Polity IV (MARSHALL; GURR; JAGGERS, 2009) e o Freedom in the World (FREEDOM HOUSE, 2010), certamente possuam seus méritos e certamente foram importantes na produção e difusão de dados quantitativos, esses índices possuem problemas sérios quando inseridos nas análises de guerras civis, sobretudo o último. As medidas oferecidas pelos dois primeiros bancos de dados também estão longe de serem perfeitas, como vimos acima; mas ao menos neles não há nada que os impeça, a priori, de serem utilizados nos estudos estatísticos sobre violência política.

Uma segunda possibilidade é a criação de novos índices de democracia, tanto a partir da combinação de medidas já existentes ${ }^{5}$, ou a partir da coleta de novos dados. A primeira alternativa é certamente mais viável e, mesmo que algumas das dificuldades apresentadas nos índices originais não possam ser superadas, elas podem ser ao menos amenizadas e fornecer resultados mais

\footnotetext{
${ }^{5}$ Como faz, por exemplo, o Scalar Index of Polities (GATES et al., 2006), índice que combina as variáveis de participação de Vanhanen (2000) e os dados do Polity IV (MARSHALL; GURR; JAGGERS, 2009). 
adequados. Gary Goertz (2006), por exemplo, mostra como é possível utilizar o Polity $I V$ de um modo distinto (e, segundo o autor, com menos ambigüidades) do que originalmente planejado pelos criadores do índice, e acreditamos que esse processo possa também ser adaptado, com proveito, para os propósitos das guerras civis. Pode-se também combinar elementos de diferentes índices para preencher lacunas ou corrigir distorções que ambos possuem: na ausência de uma variável de participação no DPI, uma boa estratégia seria mesclar os dados disponíveis em Vanhanen (2000) ou mesmo adotar medidas de participação ainda não testadas nos trabalhos de guerras civis, como a oferecida por Paxton et al. (2003), que analisa se eles possuem algum impedimento legal para votar. São muitas as combinações, e levá-las adiante enriqueceria o debate sobre os regimes e as guerras civis.

Uma terceira possibilidade, e que vem ganhando espaço na literatura mais recente (CAREY, 2007; FJELDE, 2010; KALYVAS, 2008; WEGENAST, 2010), é a utilização de variáveis mais específicas desses índices. Em um interessante artigo, Carey (2007) analisa a relação não dos índices agregados, mas apenas da competitividade do poder executivo e as guerras civis na África Sub-Saariana. Apesar do estudo ter menos generalidade e levar um número menor de aspectos dos regimes políticos em consideração, ele com certeza ganha em especificidade e consistência interna. Os resultados são mais facilmente explicáveis e, pelo fato de variáveis que medem o poder executivo estarem disponíveis em mais de um índice de democracia, puderam ser testados com mais robustez. 0 uso de variáveis desagregadas talvez seja o rumo mais promissor das pesquisas sobre guerras civis, apesar desses estudos ainda esbarrarem na falta de dados mais específicos a respeito do funcionamento das variáveis em um nível local (KALYVAS; KOCHER, 2007, p. 185). Ainda assim, há espaço para explorar comparações entre dados já disponíveis e ainda não utilizados nas pesquisas de guerras civis e, apesar de perde-se um pouco da validade externa, as melhorias em validade interna podem iluminar aspectos antes desconhecidos aos analistas (KALYVAS, 2008, p. 398).

0 campo de estudo das guerras civis está, com efeito, passando por uma crescente diversificação temática e por um contínuo refinamento de suas técnicas de mensuração empírica (BLATTMAN; MIGUEL, 2010). Como atesta Bethany Lacina (2004), as guerras civis migraram, talvez definitivamente, "do plano secundário para o palco principal" de nossa disciplina, mas a pouca atenção às bases teóricas de seu estudo e a ausência de um consenso acerca de quais variáveis 
são as mais importantes para determinar o surgimento de uma guerra civil mostram que ainda há muito por se fazer. De certo modo, tais questionamentos refletem as dificuldades de um "programa de pesquisa embrionário" (DIXON, 2009, p. 731), no qual até agora não emergiu um paradigma conceitual que sirva como uma importante referência para estudos presentes e futuros. A teoria das guerras civis, por assim dizer, ainda não encontrou seu Clausewitz; mas não podemos desistir de procurá-lo.

\section{REFERÊNCIAS}

BECK, Thorsten et al. New tools in comparative political economy: the database of political institutions. World Bank Economic Review, Washington, v. 15, n. 1, p. 165-176, Set. 2001.

BLATTMAN, Christopher; MIGUEL, Edward. Civil war. Journal of Economic Literature, Nashville, v. 48, n. 1, p. 3-57, Mar. 2010.

CAREY, Sabine C. Rebellion in Africa: disaggregating the effect of political regimes. Journal of Peace Research, London, v. 44, n.1, p. 47-64, Jan. 2007.

COLLIER, Paul; HOEFFLER, Anke. Greed and grievance in civil war. Oxford Economic Papers, Oxford, v. 56, n. 4, p. 563-595, Ago. 2004.

COLLIER, Paul; SAMBANIS, Nicholas (Org.). Understanding civil war: evidence and analysis. Washington: World Bank Publications, 2005. v. 1.

DAHL, Robert. Poliarquia: participação e oposição. São Paulo: Universidade de São Paulo, 1997.

DIXON, Jeffrey. What causes civil wars? integrating quantitative research findings. International Studies Review, v. 11, n. 4, p. 707-735, Dez. 2009.

FEARON, James. Civil war since 1945: some facts and a theory. In: ENCONTRO ANUAL DA ASSOCIAÇÃO AMERICANA DE CIÊNCIA POLÍTICA, 2005, Washington. Anais... Washington, 2005. p. 1-35.

FEARON, James; LAITIN, David. Ethnicity, insurgency and civil war. American Political Science Review, Baltimore, v. 97, n. 1, p. 75-90, Feb. 2003.

FJELDE, Hanne. Generals, dictators and kings: authoritarian regimes and civil conflict, 1973-2004. Conflict Management and Peace Science, v. 27, n. 3, p. 195-218, Jul. 2010. 
FREEDOM HOUSE. Methodology. 2010. Disponível em: <http://freedomhouse. org/template.cfm?page=351\&ana_page=363\&year=2010>. Acesso em: 17 maio 2011.

GATES, Scott et al. Institutional inconsistency and political instability: polity duration, 1800-2000. American Journal of Political Science, Austin, v. 50, n. 4, p. 893-908, Out. 2006.

GHOBARAH, Adam Hazen; HUTH, Paul; RUSSETT, Bruce. The post-war public health effects of civil conflict. Social Science and Medicine, v. 59, n. 4, p. 869-884, Ago. 2004.

GLEDITSCH, Nils Petter et al. Armed conflict 1946-2001: a new dataset. Journal of Peace Research, London, v. 39, n. 5, p. 615-637, Set. 2002.

GOERTZ, Gary. Social science concepts: a user's guide. Princeton: Princeton University Press, 2006.

HEGRE, Havard. Disentangling democracy and development as determinants of armed conflict. 9 de Janeiro de 2003. Disponível em: <http://aceproject.org/ ero-en/topics/elections-security/24637_ddcwwb.pdf/view>. Acesso em: 13 jun. 2011.

HEGRE, Havard et al. Towards a democratic civil peace? democracy, political change and civil war, 1816-1992. American Political Science Review, Baltimore, v. 95 , n. 1, p. 33-48, Mar. 2001.

HEGRE, Håvard; SAMBANIS, Nicholas. Sensitivity analysis of empirical results on civil war onset. Journal of Conflict Resolution, Newbury Park, v. 50, n. 4, p. 508535, Ago. 2006.

KALYVAS, Stathis. The logic of violence in civil war. Cambridge: Cambridge University Press, 2006.

. Promises and Pirfalls of an emerging research program: the Microdynamics of civil war. In: KALYVAS, Stathis; SHAPIRO, Ian; MASOUD, Tarek (Org.). Order, conflict and violence. Cambridge: Cambridge University Press, 2008. p. 397-421.

KALYVAS, Stathis; KOCHER, Matthew Adam. How 'Free' is Free Riding in Civil Wars? violence, insurgency, and the collective action problem. World Politics, v. 59, n. 2, p. 177-216, Jan. 2007. 
KEEFER, Philip. DPI2010: database of political institutions: changes and variable definitions. 2010. Disponível em: <http://siteresources.worldbank.org/INTRES/ Resources/469232-1107449512766/DPI2010_Codebook2.pdf>. Acesso em: 18 jun. 2011.

LACINA, Bethany. From side show to centre stage: civil conflict after the cold war. Security Dialog, v. 35, n. 2, p. 191-205, Jun. 2004.

LAKE, David; ROTHCHILD, Donald. Containing fear: the origins and management of ethnic conflict. International Security, Cambridge, v. 21, n. 2, p. 41-75, Out. 1996.

MARSHALL, Monty G.; GURR, Ted;JAGGERS, Keith. Polity IV Project: dataset users' manual. Maryland: University of Maryland, 2009. Disponível em: <http://www. systemicpeace.org/inscr/p4manualv2009.pdf>. Acesso em: 7 jun. 2011.

MUNCK, Gerardo; VERKUILEN, Jay. Conceptualizing and measuring democracy: evaluating alternative indices. Comparative Political Studies, Beverly Hills, v. 35, n. 1, p. 5-34, Feb 2002.

PAXTON, Pamela; BOLLEN, Kenneth; LEE, Deborah M.; KIM, HyoJoung. A HalfCentury of Suffrage: new data and a comparative analysis. Studies in Comparative International Development, Saint Louis, v. 38, n. 1, p. 93-122, 2003.

SAMBANIS, Nicholas. Using case studies to expand economic models of civil war. Perspectives on Politics, New York, v. 2, n. 2, p. 259-279, Jul. $2004 a$.

. What is civil war? conceptual and empirical complexities of an operational definition. Journal of Conflict Resolution, Newbury Park, v. 48, n. 6, p. 814-858, Dez. 2004 b.

SARKEES, Meredith Reid; SCHAFER, Phil. The correlates of war data on war: an update to 1997. Conflict Management and Peace Science, v. 18, n. 1, p. 123-144, Feb. 2000.

STOHL, Michael et al. State violation of human rights: issues and problems of measurement. Humans Rights Quarterly, Baltimore, v. 8, n. 4, p. 592-606, Nov. 1986.

STRAND, Havard. Reassessing the civil democratic peace. 2006. Disponível em: $<$ http://www.prio.no/files/manual-import/Strand_Thesis.pdf $>$. Acesso em: 2 maio 2011.

OS REGIMES POLÍTICOS E AS GUERRAS CIVIS...

D. FreIRE $\bullet 251$ 
. Retreating from a civil democratic peace? revisiting the relationship between political institutions and civil war. 2007. Disponível em: < http://www. prio.no/files/manual-import/strand_2007.pdf>. Acesso em: 5 ago. 2010.

UPPSALA CONFLICT DATA PROGRAM/PEACE RESEARCH INSTITUTE OSLO. Armed Conflict Dataset, 2009. Disponível em: <http://www.ucdp.uu.se/> Acesso em 22/08/2010.

VANHANEN, Tatu. A new dataset for measuring democracy, 1810-1998. Journal of Peace Research, London, v. 37, n. 2, p. 251-265, Mar. 2000.

VREELAND, James Raymond. The effect of political regime on civil war: unpacking anocracy. Journal of Conflict Resolution, Newbury Park, v. 52, n. 3, p. 401-425, Jun. 2008.

WEGENAST, Tim. Inclusive Institutions and the Onset of Internal Conflict in Resource-rich Countries. GIGA Working Papers, no 126, Hamburgo, mar/2010, p. 1-36. Disponível em: <http://www.giga-hamburg.de/content/publikationen/pdf/ wp126_wegenast.pdf> Acesso em 04/08/2010.

ZIMERMAN, Artur. Peguem a foice e vamos à luta: determinantes agrários da guerra civil. São Paulo: Humanitas, 2008.

ZIMERMAN, Artur; ALVES, Hélio Ricardo do Couto. Governmental repression and Likelihood of civil war onset: world analysis, 1981-1997. Revista de Ciência Política, Rio de Janeiro, v. 27, n. 2, p. 49-65, 2007. 